\title{
Effects of Gelam and Acacia honey acute administration on some biochemical parameters of Sprague Dawley rats
}

Suhana Samat ${ }^{1}$, Nor Azmi Md Nor ${ }^{1}$, Fuzina Nor Hussein ${ }^{2}$ and Wan Iryani Wan Ismail ${ }^{*}$

\begin{abstract}
Background: Since ancient times, honey has been used for medicinal purposes in many cultures; it is one of the oldest and most enduring substances used in wound management. Scientific evidence for its efficacy is widely studied, but systemic safety studies are still lacking. It is essential to study the impact of consumption of honey on the health and proper development of the consumer. Therefore, the present study was designed to observe the effects of acute administration (14 days) of Gelam honey (GH), a wild harvesting honey and Acacia honey (AH), a beekeeping honey, on male and female Sprague Dawley (SD) rats.
\end{abstract}

Methods: An acute oral study was performed following OECD test guideline 423, with minor modifications. In the study, GH, AH and sucrose (S) were administered at $2000 \mathrm{mg} / \mathrm{kg}$ body weight. Animals were observed for the next 14 days. Gross pathology was performed at the end of the study. Animals were observed for mortality, morbidity, body weight changes, feed and water intake. Clinical biochemistry, gross pathology, relative organ weight and histopathological examination were performed.

Results: Rats fed with honey did not exhibit any abnormal signs or deaths. Results showed a decrease in weight gain and energy efficiency, but significantly increased in total food intake and total calories in female rats fed with $\mathrm{GH}$, compared to control $(p<0.05)$. Nevertheless, a significant increase in body weight was observed in male rats in all honey-treated groups. Male rats fed with AH significantly decreased in total food intake, total calories and energy efficiency. Both male and female rats fed with GH displayed a significant decrease in triglycerides compared to control group. Hepatic and renal function levels were within acceptable range. The gross necropsy analysis did not reveal changes in any of the organs examined.

Conclusions: Our results suggest that acute consumption of $\mathrm{GH}$ and $\mathrm{AH}$ at $2000 \mathrm{mg} / \mathrm{kg}$ body weight of male and female SD rats has some discrepancy effects on biochemical parameters but in line with OECD regulation. Gelam honey may have potential in controlling weight gain and triglyceride levels in female rats compared to Acacia honey. SD rats have some effect on biochemical parameters, an exploration of which would make for intriguing analysis.

Keywords: Acacia honey, Acute consumption, Gelam honey, Sprague Dawley rats

\footnotetext{
* Correspondence: waniryani@gmail.com

${ }^{1}$ Clinical BioPharmaceutics Research Group (CBRG), Brain and Neuroscience Core, Universiti Teknologi MARA, 40450, Shah Alam, Selangor Darul Ehsan, Malaysia and Faculty of Pharmacy, Universiti Teknologi MARA, Puncak Alam Campus, 42300 Bandar Puncak Alam, Selangor Darul Ehsan, Malaysia Full list of author information is available at the end of the article
} 


\section{Background}

Honey, a sweet and viscous fluid, has medicinal properties at both preventive and curative levels. Since ancient times it has been known to have anti-bacterial, antioxidant and wound-healing constituents [1]. Moreover, honey also exhibits anti-tumor activity, with pronounced anti-metastatic and anti-angiogenic effects [2], and antibacterial, anti-inflammatory, immune-stimulant, antiulcer and wound-/burn-healing properties [3]. Various signalling pathways mediated by honey and its major components (such as chrysin, pinobanksin, vitamin C, catalase, and pinocembrin) have been unravelled recently, including stimulation of tumor necrosis factor-alpha (TNF- $\alpha$ ), inhibition-cell proliferation, apoptosis induction and cell cycle arrest, as well as lipoprotein oxidation [4]. Apart from the components mentioned above, honey also contains a variety of other biologically active compounds, such as flavonoids, vitamins, and antioxidants, as well as hydrogen peroxide $\left(\mathrm{H}_{2} \mathrm{O}_{2}\right)$, which make it an extraordinary food, possessing potent and varied medical properties [5].

Honey is produced from many different floral sources, and its biochemical and pharmacological activities vary depending on its origin and processing. In Malaysia, varieties of honey may be divided into floral honey (such as honey harvested from trees including Gelam, Tualang, Pineapple, and Coconut) and honeydew honey (for instance Acacia honey) [6]. For this study, a floral honey (Gelam honey, or GH) and a honey from honeydew honey (Acacia honey, or AH) were selected. They are both widely produced and consumed in Malaysia, and both exhibit antioxidant activity [7]. GH is produced by Apis mellifera, a honey bee, from Melalucae cajupati tress, particularly from the eastern part of Malaysia and harvest widely from the forest. It contains high levels of polyphenols and of non-phenol contents, compared to pineapple and coconut honey. $\mathrm{AH}$ is also produced by $A$. mellifera, but from the Acacia magnium plants, especially in north Malaysia and collected from a beekeeping farm. It also contains phenolic acids and flavonoids $[8,9]$.

Rigorous research studies have been conducted on honey; however, only a few studies to date have taken cognizance of the possible consumption effects of $\mathrm{GH}$ and AH. For instance, Kassim et al. (2012) [1] documented acute analysis of GH on mice (Balb/c mice) and New Zealand white rabbits at doses of 10,60,300, and $600 \mathrm{mg} / \mathrm{kg}$, diluted with saline. However, an acute study of $\mathrm{GH}$ and $\mathrm{AH}$ with doses of $2000 \mathrm{mg} / \mathrm{kg}$ body weight on Sprague Dawley rats according to OECD guideline has not been carried out, even though these rats have been used intensively in honey studies. Therefore, this study aims to observe the effects of acute administrations of $\mathrm{GH}$ and $\mathrm{AH}$ at single doses of $2000 \mathrm{mg} / \mathrm{kg}$ of body weight.

\section{Methods}

\section{Sample collection}

Gelam honey $(\mathrm{GH})$ was collected from Gelam forest, Terengganu, Malaysia. Acacia honey (AH) was purchased from beekeeping farm under the Department of Agriculture, Johor, Malaysia. The samples were irradiated with $25 \mathrm{kGy}$ gamma radiation using the radioactive source cobalt 60 (model JS8900), at the Malaysian Nuclear Agency (MINT), Selangor, Malaysia [10]. The irradiated honey was then kept at $4^{\circ} \mathrm{C}$, away from direct sunlight, in amber bottles. Sucrose (S) was purchased from Sigma-Aldrich St. Louis, MO, USA.

\section{Experimental animal husbandry}

The experimental protocol was approved by the Research Committee on the Ethical Use of Animals (UITM Care), Reference No. 05/2012. Twenty healthy Sprague Dawley (SD) rats of both sexes were obtained from Laboratory Facilities of Animal Management (LAFAM), University Technology MARA (UITM), Puncak Alam, Selangor, Malaysia. At the commencement of study, each rat was eight weeks old and weighed between 180 and $220 \mathrm{~g}$. The rats were housed at one rat per cage and maintained in standard environmental conditions under an ambient temperature of $25 \pm 2^{\circ} \mathrm{C}$ and $40-65 \%$ relative humidity, with a 12-hour light/dark cycle. They were fed with certified rodent food (Rodent Diet Speciality Feeds, Glen Forrest, Australia) and drinking water was available ad libitum. The animals were acclimatized for five days prior to the commencement of the study, and appropriately labelled. A completely randomised design was used to divide the rats into four groups, each made up of five females and one male. The control rats were orally administered with distilled water and rodent food ad libitum (Group 1), fed with GH (2000 mg/kg body weight) (Group 2), fed with $2000 \mathrm{mg} / \mathrm{kg}$ body weight of AH (Group 3), and fed with sucrose (2000 mg/ kg body weight) (Group 4).

\section{Acute administration test}

In the study, the acute oral test was performed according to the guidelines of the Organisation for Economic Co-operation and Development (OECD) for the testing of chemicals, TG 423 with slight modifications [11]. It measures adverse effects following oral administration of a single dose of a substance (or multiple doses given within 24 hours) such as general behaviour, respiratory pattern, cardiovascular signs, motor activities, reflexes, and changes in skin and fur texture. From this experiment, the $\mathrm{LD}_{50}$ (or median lethal oral dose, which is the statistically derived single dose of substance that can be expected to cause death in $50 \%$ of animals when administered by the oral route) was determined. The $\mathrm{LD}_{50}$ value is expressed in terms of weight of test substance per unit weight of test animal $(\mathrm{mg} / \mathrm{kg})[11]$. 
Initially, rats were deprived of food, except for water, for twelve hours, and weighed prior to the experiment. Test substances at a dose of $2000 \mathrm{mg} / \mathrm{kg}$ body weight were given orally, once to each group, but the control group was administered with distilled water. The test groups (Groups 2, 3 and 4) received single oral doses of $2000 \mathrm{mg} / \mathrm{kg}$ body weight of $\mathrm{GH}, \mathrm{AH}$ and S respectively. The doses given were calculated according to each animal's body weight at the week of treatment specified (Table 1). Body weights of the rats were then recorded every day. Meanwhile, mortality and the clinical signs of toxicity were observed at $0.5,1,2$ and 4 hours, and thereafter once a day for the next 14 days. On day 15, the overnight-fasted animals (water allowed) were euthanized using diethyl ether and subjected to gross pathological examination of all the major internal organs, such as heart, lung, liver, kidney and spleen.

\section{Body weight and meal pattern analysis}

The body weight (BW) of each rat was recorded once per week, and the differences in BW were noted. In the meal pattern analysis, the amount of food and water consumed was measured weekly by subtracting from the quantity of food and water supplied initially. Food efficiency was calculated once, at the end of the study. The total number of kilocalories that each rat consumed was determined by multiplying the caloric content of 1 gram of each diet by the total quantity of food eaten [12].

\section{Biochemical analysis}

Rats were fasted overnight, anaesthetised using diethyl ether, and sacrificed at the end of the experiment. Blood samples were freshly collected through cardiac puncture, and the samples were stored in EDTA tubes for serum biochemical assay. The blood samples were centrifuged at 2000 revolutions per minute (rpm) for 15 minutes at $4^{\circ} \mathrm{C}$. The clear serum obtained was separated and labelled for analysis of serum levels for the hepatic function tests, including aspartate aminotransferase (AST), alanine transaminase (ALT), a renal function test (urea and creatinine) and serum lipid profile (glucose, triglycerides (TG) and total cholesterol) [13]. These levels were determined using an Auto Analyser (ILAB 300 Plus
Clinical Chemistry Analyser, Milano, Italy) according to manufacturer's protocols.

\section{Histological evaluation}

A comprehensive gross observation was carried out on the internal organs, such as the liver, spleen, lung, kidneys and heart. They were observed for any signs of abnormality and for the presence of lesions owing to any effects of the administration of $\mathrm{GH}, \mathrm{AH}$ and $\mathrm{S}$ [13]. The organs were then carefully dissected, cleaned of any fats and weighed. The relative organ weight (ROW) of each organ was then calculated according to the following equation:

$$
\begin{aligned}
\text { ROW }= & \text { (absolute organ weight }(\mathrm{g}) \times 100) \\
& \text { /body weight of rat on sacrifice day }(\mathrm{g})
\end{aligned}
$$

Each organ was then preserved in $10 \%$ buffered formalin for subsequent histopathological examination. The tissues were embedded in paraffin, and then sectioned; the sections were cut at 4-5 microns with the rotary microtone, stained with hematoxylin and examined microscopically [14].

\section{Statistical analysis}

Results were expressed as mean \pm standard average mean (SEM). Statistical significance was determined by oneway analysis of variance (ANOVA). Values with a confidence level of $\mathrm{p} \leq 0.05$ were considered significant.

\section{Results}

\section{Acute administration study}

There were no treatment-related deaths and no abnormal signs developed in any group throughout the 14-day study. Moreover, throughout the study, no apparent differences in physical activity or other behaviours, no significant changes in the nature of stool, urine and eye colour of any rat, no diarrhoea, salivation, convulsion, sleep or coma (which are signs associated with oral toxicity) and no significant loss of fur or skin lesions were observed. The acute study showed that rats fed with $\mathrm{GH}, \mathrm{AH}$ and $\mathrm{S}$ did not result in any mortality; thus, we cannot determine $\mathrm{LD}_{50}$ from the study, i.e. the $\mathrm{LD}_{50}$

Table 1 Body weight of rats in the acute toxicity study of the treated groups - Control, Gelam honey (GH), Acacia honey (AH) and Sucrose (S)

\begin{tabular}{lccc}
\hline Group & \multicolumn{2}{c}{ Male } & \multicolumn{2}{c}{ Female } & Initial body weight \\
\cline { 2 - 4 } & Initial body weight & Final body weight & $210.14 \pm 6.70$ \\
\hline Control & $187.14 \pm 8.89$ & $272.68 \pm 9.43$ & $204.98 \pm 2.71$ \\
$(\mathrm{GH})$ & $187.32 \pm 9.34$ & $275.22 \pm 10.75$ & $206.14 \pm 2.87$ \\
$(\mathrm{AH})$ & $184.52 \pm 4.52$ & $279.58 \pm 6.26$ & $270.708 .62 \pm 5.40$ \\
$(\mathrm{~S})$ & $187.46 \pm 10.46$ & $279.94 \pm 11.06$ & $272.72 \pm 12.23$ \\
\hline
\end{tabular}

Results are reported as mean $\pm \operatorname{SEM}(n=5)$. 
value would be greater than $2000 \mathrm{mg} / \mathrm{kg}$ body weight. According to the Globally Harmonised System of Classification and Labelling of chemicals, $\mathrm{GH}$ and $\mathrm{AH}$ at $2000 \mathrm{mg} / \mathrm{kg}$ body weight may be classified as Category 5 , which is safe for consumption.

\section{Body weight}

In female rats, body weight gain of the group fed with $\mathrm{GH}$ and $\mathrm{AH}$ showed slightly reduction compared to the control group (Table 1 and Figure 1). Meanwhile, body weight gain observed in male rats in $\mathrm{GH}, \mathrm{AH}$ and $\mathrm{S}$ groups showed a significant increase $(\mathrm{p}<0.05)$ (Table 1 and Figure 1). The percentage reductions in body weight of rats fed with $\mathrm{GH}$ and $\mathrm{AH}$ were $2.38 \%$ and $2.49 \%$ respectively, compared to control.

\section{Meal pattern}

Total food intake for the female rats fed with GH exhibited significant increase compared to the control group. However, mean total food intake in male rats fed with $\mathrm{AH}$ and $\mathrm{S}$ decreased significantly. Concomitantly, total calories for female rats fed with $\mathrm{GH}$ were significantly increased (4277.71 J) compared to the control group of rats $(3541.63 \mathrm{~J})$. Meanwhile, calories in male rats fed with $\mathrm{S}$ and $\mathrm{AH}$ were significantly $(\mathrm{p}<0.05)$ decreased (2244.33 J) and $2308.07 \mathrm{~J}$, when compared to control and $\mathrm{GH}$ groups (Figure 2). Male rats fed with sucrose had significantly increased energy efficiency (0.0412) compared to control (0.0314) and GH (0.031). Female rats fed with $\mathrm{GH}(0.016)$ and $\mathrm{AH}(0.0185)$ respectively demonstrated decreased in an energy efficiency compared to the control (0.0197).

\section{Hepatic function indices}

The results obtained for serum levels of AST showed a significant decrease in rats fed with $\mathrm{GH}$ and with $\mathrm{AH}$ (Table 2), but not for rats fed with $S$ (in male rats). However, in female rats, $\mathrm{AH}$ and $\mathrm{S}$ levels showed a significant increase (to $154 \mathrm{U} / \mathrm{L}$ and $146 \mathrm{U} / \mathrm{L}$ ) compared to control (112 U/L). Meanwhile, results for ALT levels showed a significant increase for all treated groups, for both male and female rats.

\section{Renal function parameters}

A dose administration (2000 mg/kg BW) of GH, AH and $S$ resulted in significant increased levels of urea and creatinine in male rats (Table 2). In urea and creatinine levels, GH showed significant $(\mathrm{p}<0.05)$ increases $(6.16$ and $41.8 \mathrm{mmol} / \mathrm{L}$ respectively) compared to control (4.50 and $20.98 \mathrm{mmol} / \mathrm{L}$ respectively). Urea and creatinine levels exhibited the highest value $(8.16 \mathrm{mmol} / \mathrm{L}$ and $60.44 \mathrm{mmol} / \mathrm{L}$ respectively) in the $\mathrm{S}$ group compared to control group $(4.50 \mathrm{mmol} / \mathrm{L}$ and $20.98 \mathrm{mmol} / \mathrm{L}$ respectively) of male rats. However, in female rats, urea level in $\mathrm{AH}$ was not significantly increased compared to control. Meanwhile, the GH group showed no significant change $(5.20 \mathrm{mmol} / \mathrm{L})$ in urea level compared to control (5.40 mmol/L) (Table 2).

\section{Serum lipid profile}

Serum TG concentrations were significantly $(\mathrm{p}<0.05)$ decreased in both male and female rat groups fed with $\mathrm{GH}$ compared to control. Meanwhile, for female rats, cholesterol level tests of $\mathrm{AH}$ did not show a significant increase compared to control. The significantly decreased levels in the TG group indicate that treatment might not have had lipogenic effects. All cholesterol, glucose and TG level tests for rats fed with $\mathrm{GH}$ and $\mathrm{AH}$ were within range [11], except for the TG test in female rats fed $S$, and the glucose test in male rats fed with $\mathrm{AH}$ and $\mathrm{S}$.

\section{Relative organ weight}

The absolute and relative organ weights of the isolated hearts, spleens, kidneys, lungs and livers from the groups were recorded and calculated (Table 3). Gross necropsy findings did not reveal changes in any of the organs examined. The relative organ weight for kidneys recorded at the end of the study showed a significant $(\mathrm{p}<0.05)$ decrease for both male and female AH rats compared with the control group. However, other organs showed no significant change in relative organ weight (ROW) in either
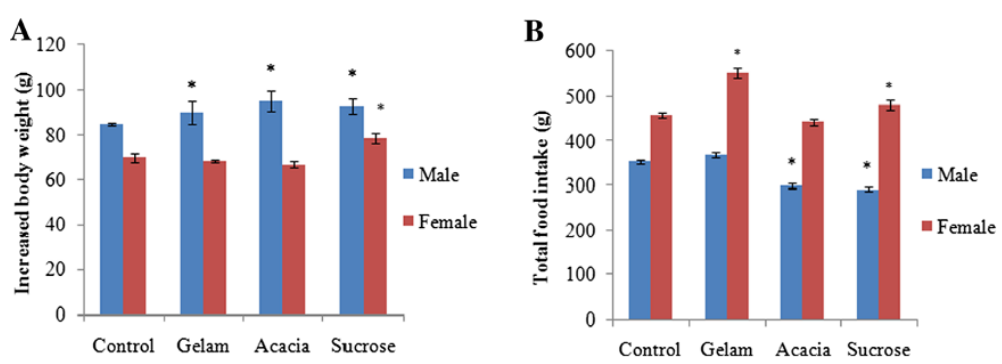

Figure 1 Effects of treated dose of control, Gelam honey (GH), Acacia honey (AH) and sucrose on (A) increased body weight in grams $(\mathbf{g})$, (B) Total food intake in grams $(\mathbf{g})$. Values are expressed as mean \pm SEM $(n=5)$. *Significant difference $(p<0.05)$ versus control. 

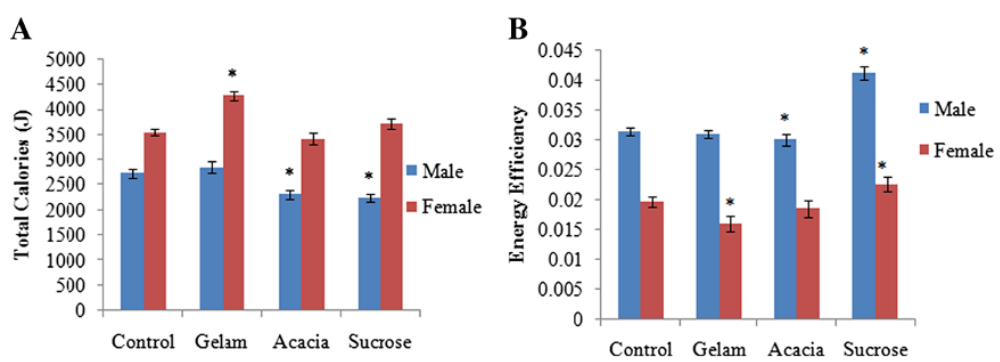

Figure 2 Effects of treated dose of control, Gelam honey (GH), Acacia honey (AH) and sucrose groups on (A) total calories (J) and (B) energy efficiency. Values are expressed as mean $\pm \operatorname{SEM}(n=5)$. *Significant difference $(p<0.05)$ versus control.

male or female rats. As shown in Table 3, the male group fed with $\mathrm{AH}$ at doses of $2000 \mathrm{mg} / \mathrm{kg}$ BW showed significantly lower weights for kidney than those of the control group. Slight changes were found in the weights of other internal organs, which may be due to the variation in size of the internal organs in each rat. Internal organ weights for the $\mathrm{GH}$ and $\mathrm{AH}$ rats were not significantly changed relative to those of the control group; except for the S/ liver weight, which was significantly increased $(3.49 \mathrm{~g}$ and $3.71 \mathrm{~g}$ ) for both male and female rats compared to control $(3.11 \mathrm{~g}$ and $3.01 \mathrm{~g})$. Gross and histopathological examinations further confirmed that the substance did not cause any tissue damage.

\section{Histopathology}

For the histological investigation, no pathological changes were observed in the livers of animals in any group (Figure 3). The macroscopic observation of the organs did not present any significant morphological or haemorrhagic changes due to the administration of any test substance. Other organs (including spleen, lung, kidneys and heart) showed no sign of pathological changes compared with the corresponding organs of the control group. For the acute test, the livers of rats on doses of $2000 \mathrm{mg} / \mathrm{kg}$ body weight (Figure 3) of $\mathrm{GH}, \mathrm{AH}$, or S did not show any changes compared to control in both male and female rats. There were no pathological changes in healthy control livers, which showed normal lobular architecture with a central vein and radiating hepatic cords [Figure 3(b)-(d)] compared to control [Figure 3(a)]. Rats fed with $\mathrm{GH}$ and $\mathrm{AH}$ alone showed no sign of damage [Figure 3(b), (c)] when compared to the control. It was composed of hexagonadal or pentagonadal lobules with central veins and peripheral hepatic triads or tetrads embedded in connective tissue. Hepatocytes were arranged in trabecules running radiantly from the central vein, and were separated by sinusoids containing Kupffer cells. They were regular and contained a large, spheroidal nucleus with a distinctly marked nucleolus distribution. Similarly, female rats fed with GH and AH showed hepatocytes in most sections [Figure 4(a)-(d)] containing clear, pale staining nuclei with one to two nucleoli [Figure 4(b)]. The cytoplasm of most hepatocytes was pale and eosinophilic, with finely granular basophilic inclusions. The hepatic sinusoids and central veins were predominantly clear of erythrocytes.

\section{Discussion}

Honey has been used for medicinal purposes in many cultures since ancient times [4]. It is one of the oldest

Table 2 Biochemical changes in rats after 14 days of acute oral administration of Control,Gelam honey (GH), Acacia honey (AH) and sucrose (S)

\begin{tabular}{|c|c|c|c|c|c|c|c|c|}
\hline & \multicolumn{4}{|c|}{ Male } & \multicolumn{4}{|c|}{ Female } \\
\hline & Control & $(\mathrm{GH})$ & $(\mathrm{AH})$ & (S) & Control & $(\mathrm{GH})$ & $(\mathrm{AH})$ & (S) \\
\hline Glucose $(\mathrm{mmol} / \mathrm{L})$ & $11.36 \pm 0.25$ & $17.60 \pm 0.42^{*}$ & $21.84 \pm 0.33^{*}$ & $22.91 \pm 0.42^{*}$ & $11.80 \pm 0.76$ & $12.62 \pm 1.52$ & $12.42 \pm 0.55$ & $12.70 \pm 0.67^{*}$ \\
\hline Urea (mmol/L) & $4.50 \pm 0.50$ & $6.16 \pm 0.38^{*}$ & $7.52 \pm 0.40^{*}$ & $8.16 \pm 0.60^{*}$ & $5.40 \pm 0.55$ & $5.24 \pm 0.44$ & $5.61 \pm 0.37$ & $5.82 \pm 0.27^{*}$ \\
\hline Creatinine & $20.98 \pm 0.81$ & $41.83 \pm 2.05^{*}$ & $52.00 \pm 2.74^{*}$ & $60.44 \pm 0.61^{*}$ & $38.00 \pm 2.50$ & $48.00 \pm 2.74^{*}$ & $54.00 \pm 5.48^{*}$ & $54.00 \pm 5.47^{*}$ \\
\hline Cholesterol (mmol/L) & $1.46 \pm 0.01$ & $1.63 \pm 0.03^{*}$ & $1.59 \pm 0.10^{*}$ & $1.77 \pm 0.10^{*}$ & $3.58 \pm 0.11$ & $3.48 \pm 0.07$ & $3.63 \pm 0.07$ & $3.58 \pm 0.06$ \\
\hline $\mathrm{TG}(\mathrm{mmol} / \mathrm{L})$ & $1.42 \pm 0.01$ & $0.72 \pm 0.02^{*}$ & $1.95 \pm 0.16^{*}$ & $1.92 \pm 0.01^{*}$ & $2.48 \pm 0.18$ & $1.46 \pm 0.21^{*}$ & $2.22 \pm 0.11^{*}$ & $2.66 \pm 0.11^{*}$ \\
\hline AST (U/L) & $108.76 \pm 0.55$ & $67.24 \pm 2.76^{*}$ & $72.22 \pm 0.23^{*}$ & $123.94 \pm 0.90^{*}$ & $112.00 \pm 4.47$ & $108.00 \pm 8.36$ & $154.00 \pm 5.48^{*}$ & $146.00 \pm 6.52^{*}$ \\
\hline $\operatorname{ALT}(\mathrm{U} / \mathrm{L})$ & $41.86 \pm 0.52$ & $45.28 \pm 0.33^{*}$ & $47.22 \pm 0.45^{*}$ & $49.36 \pm 0.23^{*}$ & $40.24 \pm 0.45$ & $65.00 \pm 5.70^{*}$ & $68.00 \pm 4.47^{*}$ & $55.00 \pm 7.07^{*}$ \\
\hline
\end{tabular}

Results are reported as mean \pm SEM $(n=5)$; ALT: alanine aminotransferase; AST: Aspartate Aminotransferase.

${ }^{*}$ Significant different $(p<0.05)$ versus control. 
Table 3 Effects in treated groups of Control, Gelam honey (GH), Acacia honey (AH) and sucrose (S) on relative organ weights (ROW) of both male and female rats

\begin{tabular}{|c|c|c|c|c|c|c|c|c|}
\hline & \multicolumn{4}{|c|}{ Male } & \multicolumn{4}{|c|}{ Female } \\
\hline & Control & (GH) & $(\mathrm{AH})$ & (S) & Control & (GH) & $(\mathrm{AH})$ & (S) \\
\hline Heart & $0.28 \pm 0.02$ & $0.28 \pm 0.02$ & $0.28 \pm 0.01$ & $0.28 \pm 0.02$ & $0.24 \pm 0.01$ & $0.31 \pm 0.01^{*}$ & $0.28 \pm 0.03$ & $0.30 \pm 0.01^{*}$ \\
\hline Spleen & $0.16 \pm 0.01$ & $0.20 \pm 0.01^{*}$ & $0.20 \pm 0.01^{*}$ & $0.19 \pm 0.02^{*}$ & $0.49 \pm 0.01$ & $0.57 \pm 0.01$ & $0.61 \pm 0.04^{*}$ & $0.72 \pm 0.01^{*}$ \\
\hline Kidney & $0.58 \pm 0.02$ & $0.6 \pm 0.01^{*}$ & $0.54 \pm 0.05^{*}$ & $0.59 \pm 0.03$ & $0.55 \pm 0.03$ & $0.60 \pm 0.04^{*}$ & $0.54 \pm 0.03$ & $0.64 \pm 0.01^{*}$ \\
\hline Lung & $0.32 \pm 0.11$ & $0.36 \pm 0.04^{*}$ & $0.32 \pm 0.01$ & $0.32 \pm 0.03$ & $0.31 \pm 0.01$ & $0.32 \pm 0.01$ & $0.32 \pm 0.01$ & $0.31 \pm 0.01$ \\
\hline Liver & $3.11 \pm 0.11$ & $3.10 \pm 0.06$ & $3.33 \pm 0.25^{*}$ & $3.49 \pm 0.18^{*}$ & $3.01 \pm 0.01$ & $3.15 \pm 0.06^{*}$ & $3.49 \pm 0.06^{*}$ & $3.71 \pm 0.10^{*}$ \\
\hline
\end{tabular}

Results are reported as mean \pm SEM $(n=5)$; ${ }^{*}$ significant different $(p<0.05)$ versus control.

and the most enduring substances used in wound management [15]. Scientific evidence for its efficacy has been widely studied $[15,16]$, but systemic safety studies are still lacking. Therefore, it is essential to study the impact of consumption of honey in animal models to ensure its impact on health compared to that of sucrose; the major sweetener used worldwide [17]. In this study, Gelam honey $(\mathrm{GH})$ and Acacia honey $(\mathrm{AH})$ were selected because they are extensively consumed in Malaysia [9].

In the acute study, a dose of $2000 \mathrm{mg} / \mathrm{kg}$ body weight, and male and female was selected, according to OECD test guideline 423. It is the limit test at the highest starting dose level and consistent approach in studying the low or non-toxicity nature of test material [11].

Results from the study reveal that the oral administration of doses of $\mathrm{GH}, \mathrm{AH}$ and $\mathrm{S}$ did not cause abnormal or alter any behavioural or physiological state of the rats in the acute tests. In female rats, body weight gain and energy efficiency of the group fed with GH showed a no significant decrease compared to the control group. Meanwhile, total food intake and total calories of the rats demonstrated a significant increase. In contrast, only body weight gain of the male rats fed with $\mathrm{AH}$ showed a significant increase $(\mathrm{p}<0.05)$ compared to control group. Weight gain by some rats could be ascribed to the nutritive compounds in honey, and its androgenic properties, since androgens exhibit anabolic activity [17]. However, hormonal factors in female rats consider playing a role in the study and required further investigation.

Analysis of blood parameters is relevant to risk evaluation of alterations in human systems [18]. In the study, no significant alterations of the biochemical parameters could be attributed to the dose given in either male or

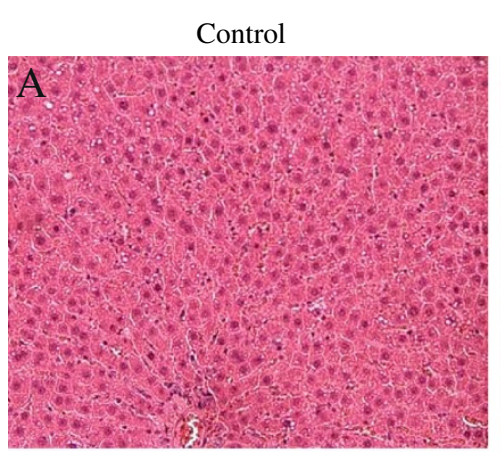

$\mathrm{AH}$

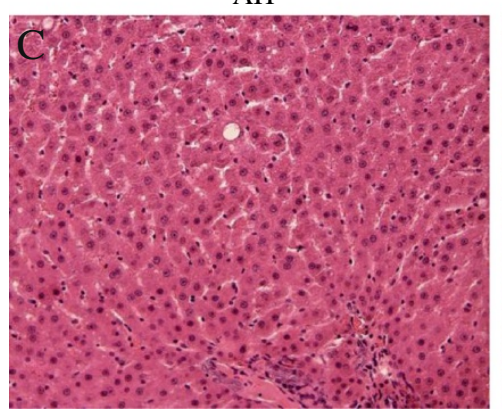

$\mathrm{GH}$

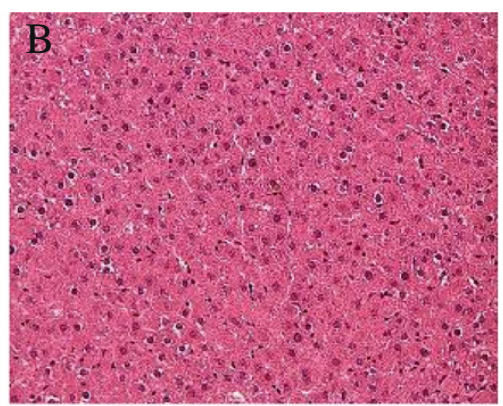

S

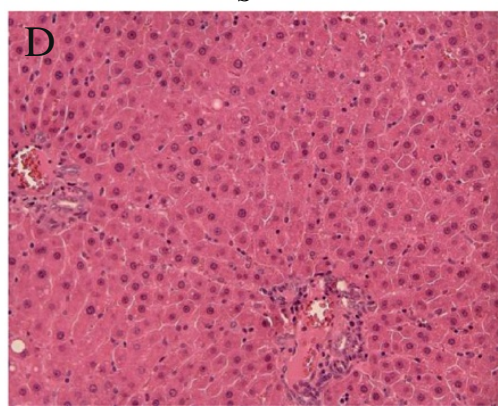

Figure 3 Photomicrograph of the male rat; A) control liver and male rat orally administered with (B) GH, (C) AH and (D) S at a dose of $2000 \mathrm{mg} / \mathrm{kg}$ body weight for 14 days (HE staining $\times 200$ ). 


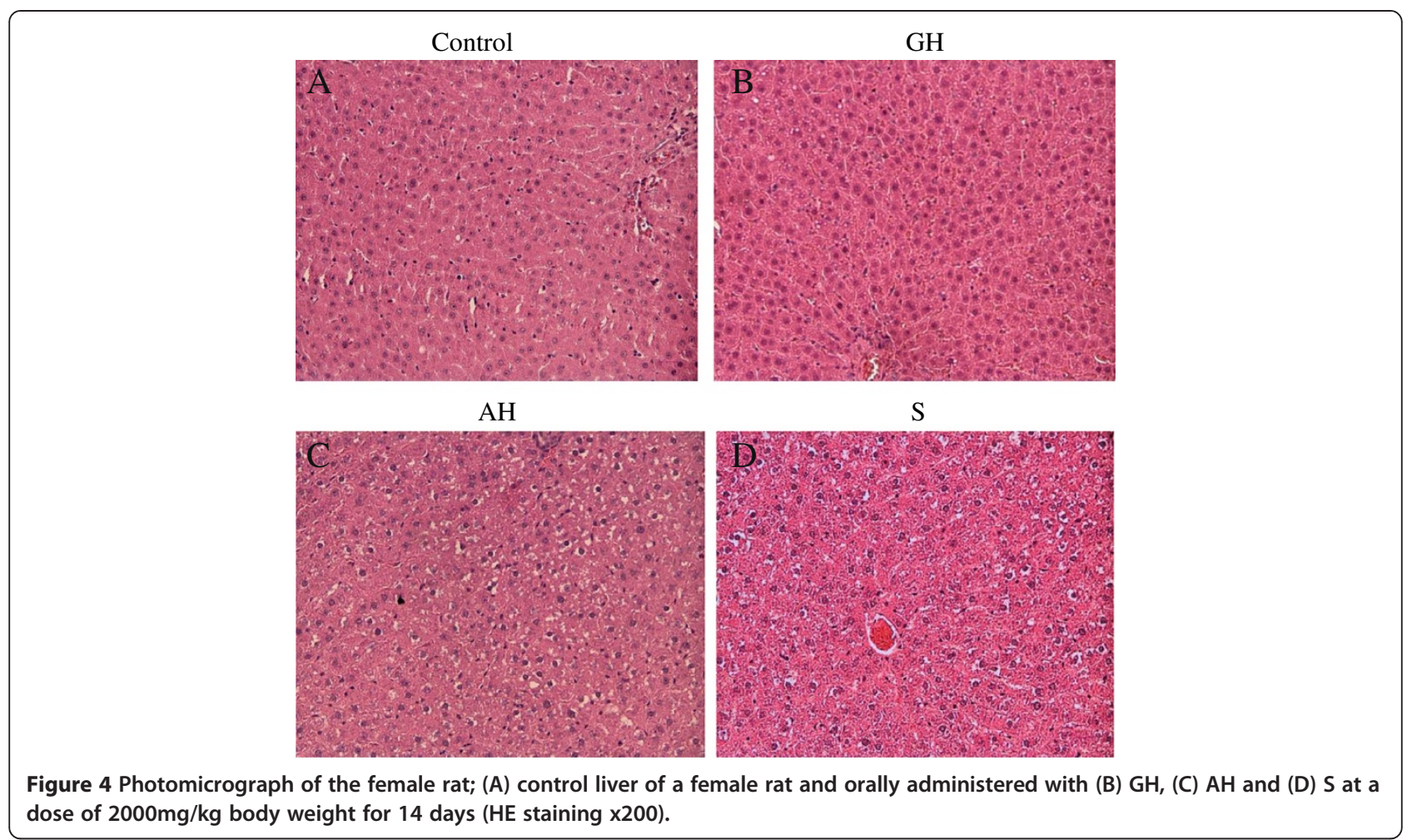

female rats. The kidney, a sensitive organ, is known to be affected by a number of factors, such as drugs or harmful substances, that ultimately lead to renal failure [19]. Assessment of possible renal damage due to $\mathrm{GH}$ and $\mathrm{AH}$ administration was made by assaying serum urea and creatinine levels. Only male rats fed with GH, $\mathrm{AH}$ and $\mathrm{S}$ resulted in significant increase levels of urea and creatinine. However, the value is still within acceptable range except for rats fed with S [11,20]. Similar finding observed on the levels of AST and ALT; which are considered to be sensitive indicators of hepatocellular damage, and can provide a quantitative evaluation of the degree of damage to the liver [21]. With the exception of sucrose, it is reasonable to deduce that GH and AH did not cause any damage to the liver and kidneys. This is further confirmed by a histological assessment of these organs, and the fact that plasma cholesterol levels remained unaffected - the latter being an indirect indicator of liver function [20].

Increment in the relative organ weight in male and female rats fed with $\mathrm{GH}, \mathrm{AH}$ and S considers normal. No difference was observed between the control and the GHand $\mathrm{AH}$-fed groups in terms of relative organ weight and structure of the other organs. Therefore, the acute study indicates that neither $\mathrm{GH}$ nor $\mathrm{AH}$ ingestion induced detrimental changes or morphological alterations in these organs, and they can be classified under Category 5, with $\mathrm{LD}_{50}$ value greater than $2000 \mathrm{mg} / \mathrm{kg}$ body weight (Globally Harmonised System of Classification and Labelling of
Chemicals, 2009). This information gives us the direct relevance of $\mathrm{GH}$ and $\mathrm{AH}$, as the dose concentration is appropriate for both human and animal consumption. This supports the wide use of honey as a therapeutic remedy, both topically and orally, and in consumer products [21].

\section{Conclusion}

The results from this study indicate that daily consumption for 14 days of Gelam honey or Acacia honey may have positive effects on body weight, meal pattern and biochemical parameters of consumers, depending on the concentration and the gender of rats. $\mathrm{LD}_{50}$ of $\mathrm{GH}$ and $\mathrm{AH}$ are both greater than $2000 \mathrm{mg} / \mathrm{kg}$ body weight, indicating the safety of the test substances. Thus, GH and AH can be classified under Category 5 of the Globally Harmonised System of Classification and Labelling of Chemicals. Present results substantiate (at least in part) the impact of consumption of $\mathrm{GH}$ and $\mathrm{AH}$, which was found to be in line with the long history of uses of honey as remedies. However, wild harvesting honey (Gelam honey) exhibit more potential effects compared to beekeeping honey (Acacia honey) in term of controlling weight gain and cholesterol level. Therefore, future work will focus on the on biochemical analysis of the long-term impact on health of the consumption of Gelam and Acacia honey. 


\section{Authors' contributions}

SS planned and carried out the experiments on Gelam honey, was involved in data interpretation, and prepared the manuscript, including revisions. NAMN planned and carried out the experiments on Acacia honey. FNH designed and planned the experiments from the animal aspect, and contributed to data interpretation. WIWI acted as project leader and advisor to this study (mainly in the use of honey in treatment), and contributed to data interpretation and troubleshooting, as well as manuscript and revision editing. All authors read and approved the manuscript.

\section{Acknowledgements}

The authors would like to acknowledge the Research Management Institute (RMI) and Jabatan Pembangunan Sumber Manusia (JPbSM) Universiti Teknologi MARA (UiTM) for providing a research grant to support the study. Appreciation also goes to Prof Aishah Adam and the Laboratory Animal Facility and Management (LAFAM), Faculty of Pharmacy, UiTM Puncak Alam, Selangor, Malaysia for the use of facilities throughout the research project. This research has been supported by the Research Entity Initiative (REI) research grant under the RMI, UiTM for the project: 600-RMI/DANA 5/3/REI (9/2013)

\section{Author details}

${ }^{1}$ Clinical BioPharmaceutics Research Group (CBRG), Brain and Neuroscience Core, Universiti Teknologi MARA, 40450, Shah Alam, Selangor Darul Ehsan, Malaysia and Faculty of Pharmacy, Universiti Teknologi MARA, Puncak Alam Campus, 42300 Bandar Puncak Alam, Selangor Darul Ehsan, Malaysia. ${ }^{2}$ Faculty of Veterinary Medicine, Universiti Putra Malaysia, 43400 Serdang, Selangor Darul Ehsan, Malaysia.

Received: 2 August 2013 Accepted: 14 March 2014 Published: 4 May 2014

\section{References}

1. Mustaffa K, Mansor M, Al-Abd N, Yusoff KM: Gelam honey has a protective effect against Lipopolysaccharide (LPS)-induced organ failure. Int Mol Sci 2012, 13(5):6370-6381.

2. Iftikhar F, Arshad M, Rasheed F, Amraiz D, Anwar P, Gulfraz M: Effects of Acacia honey on wound healing in various rat models. Phytother Res 2010, 24:583-586.

3. Khalil MI, Sulaiman SA, Boukraa L: Antioxidant properties of honey and its role in preventing health disorder. The Open Nutraceuticals Journal 2010, 3:6-16.

4. Aljadi AM, Kamaruddin MY: Evaluation of the phenolic contents and antioxidant capacities of two Malaysian floral honeys. Food Chem 2004, 85:513-518.

5. Wilson Jl: Effects of honey on sialidase activities in blood and liver of adult Wistar rats. Global Advanced ResJ Med Med Sci 2012, 1(2):40-44.

6. Uthurry CA, Hevia D, Gomez-Cordoves C: Role of honey polyphenols in health. Journal of ApiProduct and ApiMedical Science 2011, 3(4):141-159.

7. Moniruzzaman M, Khalil MI, Sulaiman SA, Gan SH: Physicochemical and antioxidant properties of Malaysian honeys produced by Apis cerana apis dorsata and apis mellifera. BMC Complement Altern Med 2013, 13(43):1-12

8. Kassim M, Achoui M, Mansor M, Al-Abd N, Yusoff KM: The inhibitory effects of Gelam honey and its extracts on nitric oxide and prostaglandin $E_{2}$ in inflammatory tissues. Fitoterapia 2010, 81(8):1196-1201.

9. Chua LS, Rahaman NLA, Sarmidi MR, Aziz R: Multi element composition and physical properties of honey samples from Malaysia. Anal Methods 2012, 135:880-887.

10. Aliyu M, Odunola OA, Faroog AD, Mesaik AM, Choudhary MI, Fatima B, Qureshi TA, Erukainure OL: Acacia honey modulates cell cycle progression, pro-inflammatory cytokines and calcium ions secretion in PC-3 cell line. Cancer Science \& Theraphy 2012, 4(12):401-407.

11. OECD/OCDE: Acute oral toxicity-acute toxic class method. OECD Guideline for the Testing of Chemicals 2001(423):1-14

12. Mohd Saleh Ahmad K, Ghazali AR, Yahya NA, Wasiman MI, Ismail Z: Acute toxicity study of standardized Mitragyna speciosa korth aqueous extract in Sprague dawley rats. J Plant Studies 2012, 1(2):120-129.

13. Lakmichi H, Bakhtaoui FZ, Gadhi CA, Ezoubeiri A, Jahiri YE, ElMansouri A, Ibtissam Z: Toxicity profile of the aqueous ethanol root extract of
Corrigiola telephiifolia pourr. (Caryophyllaceae) in rodents. Evidence-Based Complement and AlternMed 2011:1-10.

14. Kamal MSA, Ghazali AR, Yahya NA, Wasiman MI, Ismail Z: Acute toxicity study of standardized Mitragyna speciosa korth aqueous extract in Sprague dawley rats. J Plant Studies 2012, 1(2):404-409.

15. Al-Waili N, Salom K, A-Ghamdi AA: Honey for wound healing, ulcers, and burns; data supporting its use in clinical practice. Sci World J 2011, 5(11):766-787.

16. Hussein SZ, Kamaruddin MY, Makpol S, Yusof YAM: Antioxidant capacities and total phenolic contents increase with gamma irradiation in two types of Malaysian honey. Molecules 2011, 16:6378-6395.

17. Chepulis LM: The effects of honey compared to sucrose, mixed sugars, and a sugar free diet on weight gain in young rats. J Food Sci 2007, 72(3):S224-\$229.

18. Brzoska MM, Moniuszko- Jakoniuk J, Pilat-Marcinkiewiczi B, Sawicki B: Liver and kidney function and histology in rats exposed to cadmium and ethanol. Alcohol \& Alcoholism 2003, 38:2-10

19. Erejuwa OO, Sulaiman SA, Wahab MS, Sirajudeen KNS, Salleh MS, Gurtu S: Hepatoprotective effect of Tualang honey supplementation in streptozotocin-induced diabetic rats. Int J Appl Res NatProd 2012, 4(4):37-41.

20. Hau J, GL Van Hoosier J: Handbook of Laboratory Animal Science. Volume 2. 2nd edition. CRC Press Publishing; 2011.

21. Oyefuga OH, Ajani EO, Salau BA, Agboola F, Adebawo OO: Honey consumption and its anti-ageing potency in white Wistar albino rats. Sch J Biol Sci 2012, 1(2):15-19.

doi:10.1186/1472-6882-14-146

Cite this article as: Samat et al.: Effects of Gelam and Acacia honey acute administration on some biochemical parameters of Sprague Dawley rats. BMC Complementary and Alternative Medicine 2014 14:146.

\section{Submit your next manuscript to BioMed Central and take full advantage of:}

- Convenient online submission

- Thorough peer review

- No space constraints or color figure charges

- Immediate publication on acceptance

- Inclusion in PubMed, CAS, Scopus and Google Scholar

- Research which is freely available for redistribution

Submit your manuscript at www.biomedcentral.com/submit
C Biomed Central 